\title{
Analysis of Vertical Multiplier on Revised National Institute for Occupational Safety and Health (NIOSH) Lifting Equation for Male Workers in Indonesia Industry
}

\author{
Erlinda Muslim ${ }^{1, a}$, Aisyah ladha Nuraini ${ }^{2, b}$, Maya Arlini Puspasari ${ }^{3, c}$ \\ ${ }^{1,2,3}$ Faculty of Engineering, Industrial Engineering Department, Universitas Indonesia, Depok 16164 \\ aerlinda@eng.ui.ac.id, ’aisyah.iadha.n@gmail.com, maya.arlini@yahoo.com
}

Keywords: NIOSH, Vertical Multiplier, Biomechanics, Physiology, Psychophysical

\begin{abstract}
Manual Material Handling (MMH) is a risky activity that causes low back pain and has become a worldwide phenomenon, not only in developed countries, but also occur in developing countries. One effort to reduce the injury caused by MMH is the Reccomended Weight Limit (RWL) equation, published by NIOSH. However, NIOSH equation is more tested and researched in European and America. Therefore, it is necessary adjustment for Indonesia people. In this paper, the author analyze the vertical multiplier factor in NIOSH equation for male workers in Indonesia. Multiplier factor is assessed using three criterias. There are biomechanics, physiology, and psychophysical. The result of this study is form of vertical multiplier equation, i.e VM $=1$ $0.0310083(68-\mathrm{V})$ and $\mathrm{VM}=1-0.00708215(68-\mathrm{V})$ for an elevation below the knuckle.
\end{abstract}

\section{Introduction}

Health and safety is one of the important factors that should be considered by people at work. If not considered, it will provide its own disadvantages for workers and companies. Based on health and safety article by [1], in 1976, the United Nations International Covenant on Economic, Social and Cultural Rights, mentioned about providing the needs of working conditions of safety and health as a human right of every worker. International Labor Organization (ILO), as well as workers' organizations worldwide, formulates the importance of productive and decent workplace.

At work, though the technology and the use of machinery continue to grow, human intervention in some jobs that require convenience and flexibility is still happening. For example is in the loading and unloading products to the pallet. The activity of load of products is often called Manual Material Handling (MMH). Manual Material Handling is an activity consisting of lifting, bending, and the twist at the torso, which is a major cause of musculoskeletal disorder and other diseases [2, 3].

MMH activities were not done properly, can give a complaint in the musculoskeletal [4]. BLS (Bureau Labor Statistics) provide reports that musculoskeletal complaints occur when lifting by $52 \%, 13 \%$ pushing and pulling activity, $13 \%$ repetitive activity, $10 \%$ bring activity, and other activities $12 \%$ [5].

In addition, according to Pope et al. (1991), the national assembly in the field of insurance reimbursement estimate that musculoskeletal disorder related to workers is given compensation payments and indirect costs of US\$ 27-56 billion in the United States [6].

$\mathrm{Wu}$ et al. (1993) explained that the injuries were caused by MMH occur evenly and has become a worldwide phenomenon, not only in developed countries but also in developing countries [7]. In efforts to reduce injuries caused by MMH, NIOSH published equations to develop a capable load limits raised by humans in a sagittal position in 1981 [8]. This equation is used to work with both hands, lifting symmetric, and work for 8 hours. This equation is based on several methods, namely biomechanical, physiological, and psychophysical in determining the load limits [9].

In 1993, NIOSH re-published the revised NIOSH Lifting Equation (NLE), a mathematical equation that consists of the Recommended Weight Limit (RWL) and Lifting Index (LI) [10]. RWL is a formulation that would result in limits on the weight that can be lifted by a healthy worker for 8 hours without increasing the risk of musculoskeletal disorder. The variable that affect the RWL is a constant load (Load Constant, LC) reduced by 6 multipliers, i.e. the horizontal distance (HM), 
vertical distance (VM), distance (DM), asymmetric (AM), frequency (FM) and classification of coupling $(\mathrm{CM})[11]$.

NIOSH equation is more tested and researched in European countries and the United States [12]. Based on the research that has been done, NIOSH equation is suitable for use in Europe and North America, but the application of the NIOSH equation in a different state of those countries is questionable $[13,14,15]$. In the research testing, NIOSH equation is used only in Europe and America. In fact, the size of the body between the people of Europe, Asia, and America is different. It can be seen from the weight, size, and posture of Americans are greater than Indonesia. Therefore, NIOSH equation needed for compliance testing with Indonesia.

The number of workers who do lifting and $\mathrm{MMH}$ activities in Indonesia, which is a developing country, are still a lot due to the nature of the type of work that is flexible and inexpensive. The difference in body size between Indonesia and the U.S. will affect the use of this NIOSH equation. Besides body size, other variables such as age, gender, posture, distance range, fast exertion, duration and frequency of work also affects the strength of the human [16]. Human power is certainly going to affect the amount of workload received by humans.

Research on the NIOSH equation for Indonesia is related to the multiplier factors in it. Therefore, the testing is needed to use this multiplier factors for the population of Indonesia. This test is to be conducted research related to testing a factor in the NIOSH equation for the people of Indonesia and conducting a literature study of several studies that have been done.

The objective in this study is to analyze the use of NIOSH Lifting equation for Indonesian people by testing variables in the equation. The variable tested in this study is the multiplier on the vertical variable. Testing is done by using the heart rate and oxygen consumption.

\section{Method}

\section{Subject}

Subject determined is male industrial workers by the number of 21 people, mostly from industry contractors. Industrial workers determined have been accustomed to doing work related to material handling activities. Other criterion is $20-40$ years old and in good health while performing experiments that will be seen from body temperature, heart rate, and blood pressure.

\section{Experimental Design}

The experiment was conducted in an open space with a setting that has been adapted to the design of experiments that were made. Equipments used are Fitmate Med that has function to measure oxygen consumption and heart rate, a table with adjustable height, ceramics as load with the size $20 \times 20 \mathrm{~cm}$ and weighing 500 grams each tile, cardboard size of $35 \times 25 \times 25 \mathrm{~cm}$, thermometer, and digital sphygmomanometer to measure blood pressure and pulse rate before the experiment.

Before conducting the experiment, subjects were given an explanation about the purpose of the study and the procedures to be performed. Then, subjects were measured to determine the health and filled data sheet required.

Subjects were then asked to perform the experiment in accordance with the design of experiments that have been made. Burden lifted will not be notified to the subjects in order to not cause psychological effects, the effect of artificial fatigue. Furthermore, the Fitmate MED is used in the subjects. Besides, the vertical distance, horizontal, and angle of symmetry are measured.

According to Snook (1978), there are three different positions for the lifting of the floor surface to the height of handgrip (knuckle height), from the height of the handgrip to shoulder height, and from shoulder height to a maximum vertical reach of hand. However, for the type of third, the experiment is not conducted in this study. This is due to the inability of respondents to lift weights from shoulder height to the height above the reach of the hand. As the result, the experiment is only done two types of height.

Frequency of lifting is 3 lifting per minute. Total length of the trial period is 30 minutes by observing 3 times with 3 different types of loads $(13 \mathrm{~kg}, 17 \mathrm{~kg}$ and $19 \mathrm{~kg}$ ) for $5 \mathrm{~min}$ for each type of load. Then, the calculation of pulse rate and oxygen consumption of the respondents in real time 
using Fitmate MED is done. After completing a kind of load, subjects will be asked about the perceived weight during lifting in accordance with the RPE scale (Rating of Perceived Exertion).

\section{Results and Discussion}

Anthropometric data collection performed on 16 subjects. The data were taken are height, weight, height knuckle and shoulder height. Anthropometric data will later be used as a data processing load capacity based on biomechanical criteria using software Jack.

Collecting data pulse, oxygen consumption, and Energy Expenditure obtained from Fitmate MED. Data are listed starting every 15 seconds for 5 minutes with the real time calculation. Then, the next step is followed by recording of the value of RPE. RPE values were recorded every completed one type of experiment.

Further measurements based on three criteria, biomechanical, psychophysical, and physiological. NIOSH Recommendations are given on the criteria of the biomechanics of loading does not produce force more than $3400 \mathrm{~N}$ force on the L4/S1 bone. This biomechanics calculations using is supported by software jack in which there are Low Back Analysis (LBA). In this jack software required anthropometric data has been obtained.

L5/S1 compressive force calculation involves the position of origin and destination. This is because these two positions is the most critical position. Therefore, when one of the torques on the origin or destination position exceeds the recommendations given the lifting, it is said to be unsafe because it can cause injury to the spine L5/S1. Here are the results for the overall LBA using Jack contained in Table 1.

Table 1. Biomechanics Calculation Results

\begin{tabular}{|c|c|c|c|c|c|}
\hline \multirow{2}{*}{ No } & \multirow{2}{*}{ Weight (Kg) } & \multirow{2}{*}{ Information } & \multicolumn{2}{|c|}{ Torque on L5/S1 (N) } & \multirow{2}{*}{ Lifting Status } \\
\cline { 3 - 5 } & & & Origin & Destination & \\
\hline \multirow{2}{*}{1} & \multirow{2}{*}{13} & Experiment 1 & 2198 & 1980 & Not at risk \\
\cline { 3 - 5 } & & Experiment 2 & 1901 & 2743 & Not at risk \\
\hline \multirow{2}{*}{2} & \multirow{2}{*}{17} & Experiment 1 & 2421 & 2291 & Not at risk \\
\cline { 3 - 5 } & & Experiment 2 & 2215 & 3270 & Not at risk \\
\hline \multirow{2}{*}{3} & \multirow{2}{*}{19} & Experiment 1 & 2552 & 2446 & Not at risk \\
\cline { 3 - 5 } & & Experiment 2 & 2351 & 3532 & Risk \\
\hline
\end{tabular}

From Table 1, it can be seen that based on the criteria of biomechanics, which has a maximum safe limit of the acceptable compressive force on L5/S1 bone $3400 \mathrm{~N}$, first experiment with each load 13 $\mathrm{Kg}, 17 \mathrm{Kg}, 19 \mathrm{Kg}$, is not risk to cause low back pain. However, in the second experiment, safe limits contained in $17 \mathrm{Kg}$ load because the load $19 \mathrm{~kg}$ give greater compression force than $3400 \mathrm{~N}$. To get a load limit based on physiological criteria, it can be seen by calculating energy expenditure with convert of heart rate upon completion. Conversions are done by the equation of energy consumption and heart rate. When categorized based on the height and length of time in lifting weights, Waters et al divided into two, namely the height is less than or equal to $75 \mathrm{~cm}$ has a limited energy of $4.7 \mathrm{kcal} / \mathrm{min}$, while the height of more than $75 \mathrm{~cm}$ has a limited energy by $3.3 \mathrm{kcal} /$ minutes. Below in Table 3 and Table 4 is a summary of the calculation results based on the criteria of physiological energy expenditure.

Table 3. Calculation Result of Energy Expenditure Based on Physiology Criteria in Experiment 1

\begin{tabular}{|c|c|c|c|c|}
\hline \multirow{2}{*}{$\begin{array}{c}\text { Weight } \\
(\text { Kg) }\end{array}$} & \multicolumn{2}{|c|}{ Average } & \multicolumn{2}{c|}{$\begin{array}{c}\text { Energy Expenditure Average } \\
\text { (kkal/menit) }\end{array}$} \\
\cline { 2 - 5 } & Dno & Dnt & initial & end \\
\hline 13 & 78,313 & 99,209 & 3,019 & 4,256 \\
\hline 17 & 78,313 & 103,863 & 3,019 & 4,568 \\
\hline 19 & 78,313 & 107,125 & 3,019 & 4,814 \\
\hline
\end{tabular}


Tabel 4. Calculation Result of Energy Expenditure Based on Physiology Criteria in Experiment 2

\begin{tabular}{|c|c|c|c|c|}
\hline \multirow{2}{*}{ Beban (Kg) } & \multicolumn{2}{|c|}{ Rata-Rata } & \multicolumn{2}{c|}{$\begin{array}{c}\text { Rata-Rata Energy Expenditure } \\
\text { (kkal/menit) }\end{array}$} \\
\cline { 2 - 5 } & Dno & Dnt & initial & end \\
\hline 13 & 78,313 & 94,934 & 3,019 & 3,919 \\
\hline 17 & 78,313 & 99,250 & 3,019 & 4,211 \\
\hline 19 & 78,313 & 101,894 & 3,019 & 4,411 \\
\hline
\end{tabular}

Based on the tables, energy expenditure that meets the requirements of the NIOSH criteria can be determined by looking at the end of the Energy Expenditure. For the first experiment, the load limit that is recommended by NIOSH is $17 \mathrm{~kg}$, while the second experiment is the safe limit at $<13 \mathrm{~kg}$ because $13 \mathrm{~kg}$ exceeds $3.3 \mathrm{kcal} / \mathrm{min}$. Both of these limitations have met the requirements of NIOSH in terms of physiological criteria.

For the second experiment, due to limits based on physiological load is less than $13 \mathrm{~kg}$, use a scatter plot graph to determine the load limit according to the criteria of $3.3 \mathrm{kcal} / \mathrm{min}$. The following Figure 1 is the result of a scatter graph of the average load on the second experiment.

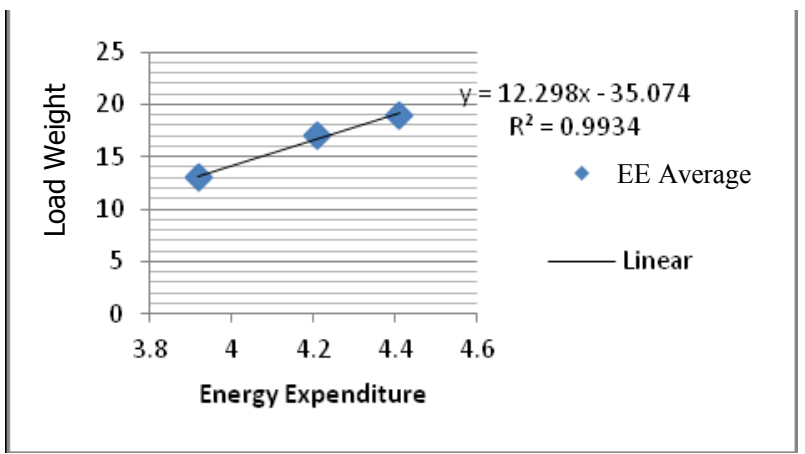

Fig 1. Graph of Load Weight vs. Energy Expenditure in Second Experiment

Based on Figure 8, it is known that the R-value obtained is equal to 0993. R-value is close to 1 , indicating the value of energy expenditure obtained has a high precision or accuracy. The equation obtained is $\mathrm{Y}=12.29 \mathrm{x}-35.07$, where $\mathrm{y}=$ weight and $\mathrm{x}=$ energy expenditure. Then, put the value of the limits set by NIOSH to a height greater than $75 \mathrm{~cm}$, which are $3.3 \mathrm{kcal} / \mathrm{min}$ into the equation. The results of these calculations indicate that the safe load limit of physiological criteria recommended by NIOSH in the second experiment is equal to $5.5094 \mathrm{Kg}$.

Oxygen consumption can be converted into energy expenditure. Fitmate MED. has done this conversion automatically. This can be proven by the linear graph between oxygen consumption with energy expenditure. Table 5 and 6 is a recap of the result of Fitmate MED energy expenditure.

Table 5. Results of Calculation Energy Expenditure Fitmate MED in Experiment 1

\begin{tabular}{|c|c|}
\hline Weight $(\mathrm{Kg})$ & $\begin{array}{c}\text { Energy Expenditure Average } \\
\text { (kkal/menit) }\end{array}$ \\
\hline 13 & 2,491 \\
\hline 17 & 2,722 \\
\hline 19 & 2,838 \\
\hline
\end{tabular}

Table 6. Results of Calculation Energy Expenditure Fitmate MED in Experiment 2

\begin{tabular}{|c|c|}
\hline Weight $(\mathrm{Kg})$ & $\begin{array}{c}\text { Energy Expenditure Average } \\
\text { (kkal/menit) }\end{array}$ \\
\hline 13 & 2,314 \\
\hline 17 & 2,650 \\
\hline 19 & 2,877 \\
\hline
\end{tabular}


Based on the tables, for the first and second experiment, the load limit is still recommended by NIOSH to $19 \mathrm{~kg}$. When viewed from Energy Expenditure (EE) that recommended by NIOSH, The value of $\mathrm{EE}$ is to $4.7 \mathrm{kcal} / \mathrm{min}$ for the first experiment and $3.3 \mathrm{kcal} / \mathrm{min}$ for the second experiment, the resulting value of EE in table 5 and 6 are still far below the recommended EE. Therefore, it safe limits for these physiological criteria generated by EE Fitmate MED for both trials are at $>19 \mathrm{Kg}$. Both of these limitations have met the requirements of NIOSH in terms of physiological criteria.

Psychophysical data processing uses RPE or Borg Scale and pulse rate after activity. Determination of RPE is to help justify the respondent performed subjectively. Based on research [17], the load of adjustment using RPE using the following formula:

\section{$\frac{R P E \times 10}{D n t} \times$ Inital Load Used}

Determination of the initial load used for the calculation of psychophysical criteria by doing a comparison on the two criteria limit load. Then, it will be got the critical load that can be lifted. According to the principle of NIOSH safety and health of workers, it is selected the minimal load limit of the two criteria, biomechanics and physiology. The results showed:

- Physiology of HR: maximum load limit based on the criteria psychophysical experiment 1 is $21.278 \mathrm{~kg}$ and for experiment 2 is $6.4705 \mathrm{~kg}$.

- Physiology of energy expenditure from Fitmate MED: the maximum load limit based on the criteria psychophysical experiment 1 is $26.604 \mathrm{~kg}$ and for experiment 2 is $23.9798 \mathrm{~kg}$.

After doing the calculations of three criteria, then it is the determination of Vertical Multiplier Factor. Vertical multiplier obtained from knuckle height factor and reduction factors recommended by NIOSH (1991) for a VM that is equal to $22.5 \%$. In determining this VM, the first thing that must be determined reduction and multipliers factor. To create a vertical multiplier according to the Indonesia, it is used anthropometric data with 5\% percentile. The use of 5\% percentile is because in order all people of Indonesia with a dimension that is not too low or high can use equation for vertical variables. According to a study titled anthropometry of the Singaporean and Indonesian Populations in 2010, the Indonesia anthropometric data obtained male body height percentiles $5 \%$ is $162 \mathrm{~cm}$ and for knuckle height is $68 \mathrm{~cm}$.

Based on the research, it is obtained 2 limits the maximum load for lifting from floor to knuckle height at $21.27 \mathrm{~kg}$ (when compared with physiological-HR) or 26,604 kg (when compared with physiological Fitmate-EE). The maximum load for lifting from knuckle height to shoulder height obtained $6.647 \mathrm{~kg}$ (when compared with physiological-HR) or $23.9798 \mathrm{~kg}$ (when compared with physiological fitmate-EE). For lifting above the shoulder is not done in this experiment because of the inability of each subject.

Reduction factors are divided into two factors. There are reduction factor above knuckle height and reduction factor under knuckle height. For reduction factors above knuckle height cannot be calculated due to the lack of data in the load calculation can be lifted from shoulder height. For reduction factors at the beginning of the floor height, the load has been obtained based upon biomechanical criteria tailored to the compressive force on the biomechanics. In the calculation of the compression force is used biomechanical models, Bloswick [18].

$\mathrm{F}_{\mathrm{c}}=3(\mathrm{BW}) \sin \theta+0.5(\mathrm{~L} * \mathrm{HB})+0.8((\mathrm{BW}) / 2+\mathrm{L})$

Having obtained the torque ratio is based on biomechanics criteria, and then if the terms of psychophysical criteria for the lifting of a height above the floor, it will give a higher weight limit than the lifting made at knuckle height, the difference is as follows:

- $\quad$ The difference the first results of the load limits $=\frac{21.27}{6.647} \times 100 \%=319.99 \%$

- $\quad$ The difference the second results of the load limits $=\frac{26.6}{23.98} \times 100 \%=110.9 \%$

Reduction factors for lifting of the initial height above the floor can be drawn from the difference between biomechanics and psychophysical criteria. Reduction factors is the difference psychophysical ability to increase the amount of torque loading experienced in a different position, which gives the following results:

- $\quad$ Reduction Factors for the first result $=319.99 \%-[(71.52 \%+146.76 \%) / 2]=210.856 \%$. 
- $\quad$ Reduction Factors for the second result $=110.9 \%-[(60.25 \%+65.32 \%) / 2]=48.2 \%$

Therefore, in this study obtained deduction for below knuckle height. For reduction factors in above the knuckle, should be re-examined if the workers cannot lift heavy loads at heights above the shoulder.

Vertical multiplier obtained from the vertical reduction factor has been obtained and knuckle height. Knuckle heights are used as constants in the equation for loading because loading in this position is the most optimal in terms of the three criteria [16]. As the result, the calculation to obtain the vertical multipliers is as follows:

- Equation form of vertical multiplier NIOSH: VM $=1-0.003|\mathrm{~V}-75|$ (for $\mathrm{cm}$ ). Number of 75 is knuckle height. $0.003|V-75|$ is reduction factor that NIOSH recommended at $22.5 \%$.

- The determination of vertical multiplier factor under knuckle height for the first result in indonesia people is $\mathrm{VM}=1-\mathrm{a}(\mathrm{V}-68)$. The value of a can be obtained from: a $\mathrm{x}(68)=210.856 \%$. $\rightarrow \mathrm{a}=0.03100829$.

- The determination of vertical multiplier factor under knuckle height for the second result in indonesia people is VM $=1-\mathrm{a}(\mathrm{V}-68)$. The value of a can be obtained from: a $\mathrm{x}(68)=48.2 \% \rightarrow \mathrm{a}$ $=0.00708215$.

\section{Conclusion}

In carrying out manual handling material handling, NIOSH has recommended imposition equation that adjusts weights can be lifted by the workers to maintain the health and safety of workers. In its application in Indonesia requires an adjustment to the equation because there are differences in anthropometric between Indonesia and the Americans who were sampled by NIOSH.

RWL equation has several multipliers. In this study, multiplier factor, which examined are vertical multiplier. Formulation of this multiplier will have optimal results when assessed using three criteria: the criteria of biomechanics, physiology, and psychophysical.

Biomechanical criterion indicates that the lifting risk is on destination load from knuckle height to shoulder height. Furthermore, the lifting, which also have a high risk, is initial position of lifting. From the results of LBA, the initial position of lifting will give lower compressive force when the higher location of the lifting is done.

Physiological criterion indicates that increasing the mass of the load then the higher energy expenditure, higher pulse rate, and the required amount of oxygen consumption also increased. In addition, the lifting of the higher positions provides load reductions. Based on physiological criteria, the higher lifting expend less energy, however, because of the safe limits of the lifting is more than $3.3 \mathrm{kcal} / \mathrm{min}$ to a height greater than $75 \mathrm{~cm}$, there was a reduction in the load limit who can be lifted as compared to less than $75 \mathrm{~cm}$. Then, there is a difference between the calculation of energy expenditure using heart rate and calculation from Fitmate MED.

Psychophysical criterion is the most subjective criteria than the other two criteria. The result of these criteria is the safest result because comparisons with biomechanical and psychophysical criteria have been done.

Results from this research are the vertical multiplier factor for lifting height under knuckle, with two results, there are:

- $\mathrm{VM}=1-0.0310083(68-\mathrm{V})$

- $\mathrm{VM}=1-0.00708215(68-\mathrm{V})$

\section{References}

[1] Modjo, Robiana. Keselamatan dan kesehatan kerja, siapa perduli?. Februari 9, 2012. http://staff.ui.ac.id/internal/132096019/publikasi/ArtikelK3 SiapaPerduliRobianaModjo.pdf. (2007). [2] Wickens, C.D., Gordon, S.E., Liu, Y. A Introduction to Human Factors Engineering. Longman, New York. (1998).

[3] Ayoub, M.M., Mital, A. Manual materials handling. London: Taylor and Francis. (1989). 
[4] Ramadha, Krisna Angga. Analisis Ergonomi para Buruh Angkut Terhadap Terjadinya Keluhan Musculoskeletal Disorders (MSDs) Menggunakan NIOSH Lifting Equation dan PEI. Depok: Universitas Indonesia. (2010).

[5] Astuti, R. D., Suhardi, B. Analisis Postur Kerja Manual Material Handling Menggunakan Metode OWAS (Ovako Work Posture Analysis System). Gema Teknik: Majalah Ilmiah Teknik Vol. 10, No. 1. (2007).

[6] [7] Swei-Pi, Wu. Psychophysically Determined Symmetric and Asymmetric Lifting Capacity of Chinese Males for One Hour's Work Shifts. Elsevier: International Journal of Industrial Ergonomics 25, 675-682. (1999).

[8] Kwan S. Lee *, Hee S. Park, Young H. Chun. The Validity of the Revised NIOSH Weight Limit in a Korean Young Male Population: A Psychophysical Approach. Elsevier: International Journal of Industrial Ergonomics 18, 181 - 186. (1996).

[9] NIOSH (National Institute of Occupational Safety and Health). Work Practices Guide for Manual Lifting. DHHS (NIOSH) Publication No. 81, 122, Cincinnati, OH. (1981).

[10] Waters, et al. Revised NIOSH Equation for the Design and Evaluation of Manual Lifting Tasks. Journal of Ergonomics Vol. 36 No. 7. (1993).

[11] Waters, et al. Accuracy of Measurement for the Revised NIOSH Lifting Equation. Elsevier: Applied ergonomics Vol. 29 No.6. (1997).

[12] Swei-Pi, Wu. Maximum acceptable weight of lift by Chinese experienced male manual handlers. Elsevier: Applied Ergonomics 28, p. 237-244. (1997).

[13] Zhu, Z., Zhang, Z. Maximum Acceptable Repetitive Lifting Workload by Chinese Subjects. Ergonomics 33, 875-884. (1990).

[14] Evans, W.A. The Relationship between Isometric Strength of Cantonese Male and the US NIOSH Guide for Manual Lifting. Applied Ergonomics 21, 135-142. (1990).

[15] Maiti, R; Ray, G.G. Determination of Maximum Acceptable Weight of Lift by Adult Indian Female Workers. International Journal of Industrial Ergonomics 2004-01-01. (2004).

[16] Mital, A., \& Ramakrishnan, A. A Comparison of Literature-Based Design Recommendations and Experimental Capability Data for a Complex Manual Materials Handling Activity. International Journal of Industrial Ergonomics, 24, 73-80. (1999).

[17] Widyanti; Ari. Analisis manual material handling serta faktor pengali vertikal dan jarak DM pada persamaan pembebanan NIOSH. Bandung: Institut Teknologi Bandung. (1998).

[18] Bloswick, D. S. Estimation of Stresses Associated with Manual Material Handling Tasks: Back $\begin{array}{llll}\text { Compressive } & \text { Force } & \text { Juni } & 1012 .\end{array}$ http://personal.health.usf.edu/tbernard/HollowHills/UtahBackCompForc11.pdf. (2000). 